\title{
Retinoic Acid Signaling: A New Piece in the Spoken Language Puzzle
}

\author{
Jon-Ruben van Rhijn ${ }^{1,2}$ and Sonja C. Vernes ${ }^{1,3 *}$ \\ 'Department of Language and Genetics, Max Planck Institute for Psycholinguistics, Nijmegen, Netherlands, ${ }^{2}$ Molecular \\ Neurophysiology Group, Department of Cognitive Neuroscience, Radboud University Medical Center, Nijmegen, \\ Netherlands, ${ }^{3}$ Donders Institute for Brain, Cognition and Behaviour, Radboud University, Nijmegen, Netherlands
}

Speech requires precise motor control and rapid sequencing of highly complex vocal musculature. Despite its complexity, most people produce spoken language effortlessly. This is due to activity in distributed neuronal circuitry including cortico-striato-thalamic loops that control speech-motor output. Understanding the neuro-genetic mechanisms involved in the correct development and function of these pathways will shed light on how humans can effortlessly and innately use spoken language and help to elucidate what goes wrong in speech-language disorders. FOXP2 was the first single gene identified to cause speech and language disorder. Individuals with FOXP2 mutations display a severe speech deficit that includes receptive and expressive language impairments. The neuro-molecular mechanisms controlled by FOXP2 will give insight into our capacity for speech-motor control, but are only beginning to be unraveled.

OPEN ACCESS

Edited by: Antonio Benítez-Burraco, University of Huelva, Spain

Reviewed by: Constance Scharff, Freie Universität Berlin, Germany Tomokazu Tomo Fukuda, Tohoku University, Japan

Christina Roeske contributed to the review of Constance Scharff

*Correspondence: Sonja C. Vernes sonja.vernes@mpi.nl

Specialty section: This article was submitted to Language Sciences, a section of the journal Frontiers in Psychology

Received: 01 September 2015 Accepted: 10 November 2015 Published: 26 November 2015

Citation: van Rhijn JR and Vernes SC (2015) Retinoic Acid Signaling: A New Piece

in the Spoken Language Puzzle. Front. Psychol. 6:1816. doi: 10.3389/fpsyg.2015.01816
Recently FOXP2 was found to regulate genes involved in retinoic acid (RA) signaling and to modify the cellular response to RA, a key regulator of brain development. Here we explore evidence that FOXP2 and RA function in overlapping pathways. We summate evidence at molecular, cellular, and behavioral levels that suggest an interplay between FOXP2 and RA that may be important for fine motor control and speech-motor output. We propose RA signaling is an exciting new angle from which to investigate how neuro-genetic mechanisms can contribute to the (spoken) language ready brain.

Keywords: retinoic acid, FoxP2, synaptic plasticity, development, motor skills, striatum, dopamine receptor

\section{SPEECH AND SPOKEN LANGUAGE}

Speech is the primary modality by which humans use language, and human orofacial morphology is uniquely suited to the production of intricate vocalizations needed for spoken language (Lieberman, 2007). The orofacial musculature is one of the most complex muscle systems in the body and in order to successfully produce meaningful speech these muscles must be controlled and coordinated in rapid sequences involving distributed neuronal circuitry. This motor activity is generated in several neural loops that select appropriate actions and generate the necessary motor patterns. One crucial circuit, the cortico-basal ganglia loop, sends activity from the motor cortex to the striatum (a component of the basal ganglia) where activity is integrated. Subsequently, outputs from here modulate activity in several thalamic nuclei. Activity from the thalamus is then sent back to the motor cortex, where a specialized population of output neurons organizes the complex thalamocortical inputs (Kravitz and Kreitzer, 2012; Calabresi et al., 2014). These cortical output neurons send the information, via the pyramidal tract, to motor neurons directly controlling muscle tissue. These neurons are either located in the spinal cord (controlling limb and body movements), or in the brainstem's cranial nerve nuclei 


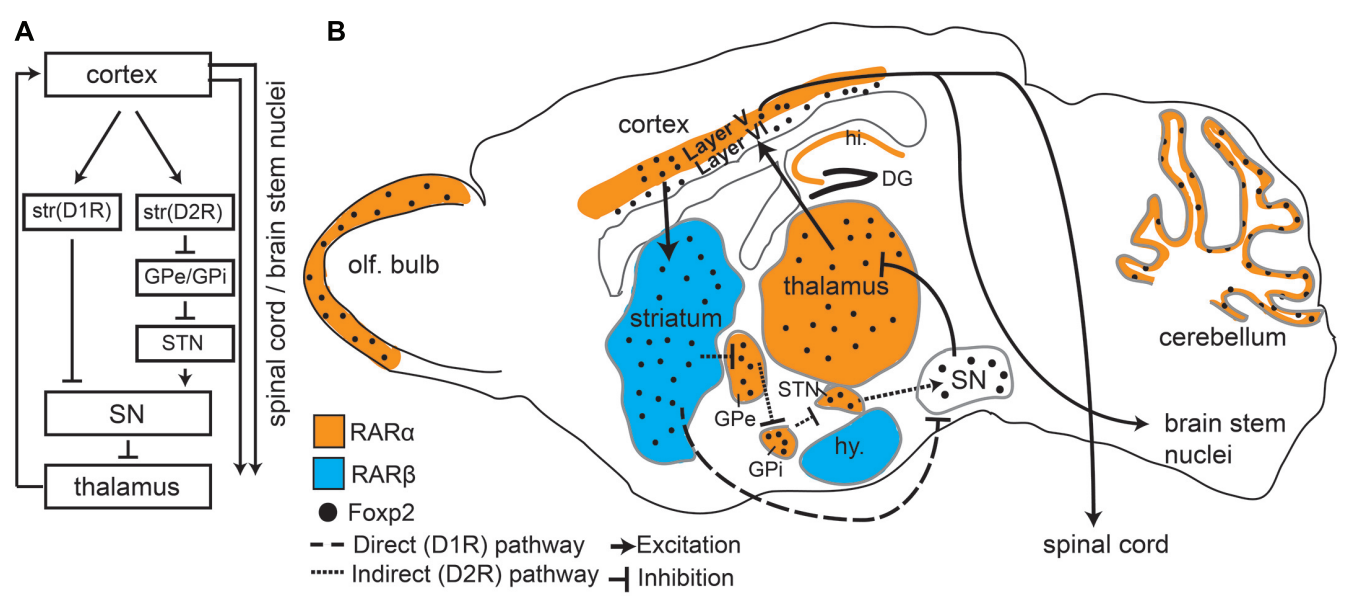

FIGURE 1 | Foxp2 and retinoic acid receptors (RARs) show overlapping expression patterns in motor associated circuitry. (A) An overview of the direct and indirect pathways represented in the sagittal view showing connectivity between different regions. Dopamine receptor type 1 (D1R) and Dopamine receptor type 2 (D2R) expressing cells in the striatum are separated to highlight direct and indirect pathways. (B) Sagittal Schematic of the mouse brain showing that Foxp2 $\mathrm{RAR} \alpha$, and RAR $\beta$ are all expressed in motor associated circuitry. RAR $\alpha$ and RAR $\beta$ are expressed in distinct regions, but each receptor partially overlaps with Foxp2. RAR $\alpha$ and Foxp2 can be found in deep layers of the cortex, thalamus, subthalamic nucleus (STN), the internal (GPi) and external (GPe) globus pallidus, cerebellum, and olfactory bulbs (OB). Foxp2 and RAR $\beta$ overlap in the striatum. RAR $\alpha$ shows non-overlapping expression in the hippocampus (hi.), RAR $\beta$ in the hypothalamus (hy), and Foxp2 in the substantia nigra (SN). Connectivity between regions involved in motor processing (including outputs to brain stem nuclei and spinal cord) is shown by solid lines. The direct (excitatory) and indirect (inhibitory) pathways, which are the two outputs from the striatum, are shown by dashed lines.

(controlling facial and vocal tract movements). An illustration of the cortico-basal ganglia loop (in the rodent brain) is given in Figure 1A. Proper connectivity within this pathway is necessary to enable the precise outputs needed for orofacial muscle control.

The striatum can be seen as a central hub within the motor pathway, making it one of the most intriguing regions in which to investigate properties of motor circuitry and orofacial control. Striatal activity is especially important for fine motor behavior and motor skill learning (Doyon et al., 2003) and cortical and subcortical circuitry, including the striatum, has been established as highly important for speech-motor control (Lieberman, 2002). Furthermore, increased activation of the basal ganglia (which incorporates the striatum) has been shown via functional brain imaging (fMRI) in specific speech-motor language tasks (Wildgruber et al., 2001; Booth et al., 2007). Lastly, morphological changes in the striatum have been described in individuals with speech problems such as stuttering (Craig-McQuaide et al., 2014) and non-fluent aphasia (Ogar et al., 2007).

The principal cell type in the striatum is the medium spiny neuron (MSN), which makes up approximately $98 \%$ of all striatal cells (Kemp and Powell, 1971; Huang et al., 1992; for review, see Kreitzer and Malenka, 2008). MSNs can be further divided into two categories of neurons that have different connectivity and opposing functions: dopamine receptor type 1 (D1R) and dopamine receptor type 2 (D2R) expressing cells (Figure 1A). D1R expressing MSNs connect to thalamic nuclei via the "direct pathway" which results in excitation of the motor cortex. D2R expressing MSNs form an "indirect pathway" that connects to the thalamus via multiple subcortical regions leading to inhibition of the thalamus and thus reduced cortical input (Figure 1A), (Albin et al., 1989; Kravitz and Kreitzer, 2012; Calabresi et al., 2014).
This balance between excitation (resulting in more movement) and inhibition (less movement) is crucial for coordinated motor function (Calabresi et al., 2014) including fine orofacial motor control.

In order to unravel the fundamental components that enable humans to effortlessly use spoken language, we will need to understand the neuro-genetic mechanisms involved in establishment, function, and maintenance of speech-motor pathways.

\section{SPOKEN LANGUAGE AND FOXP2}

A breakthrough in speech and language genetics came with the identification of the first gene to cause a speech/language disorder: FOXP2 (Lai et al., 2001). Mutations in FOXP2 were found in a large pedigree known as the KE family (Hurst et al., 1990; Fisher et al., 1998; Lai et al., 2001). Affected family members were diagnosed with a severe speech impairment known as developmental verbal dyspraxia (also known as childhood apraxia of speech; OMIM: 602081) and carried a mutation in one copy of their FOXP2 gene. In addition to speech impairments, affected family members demonstrated receptive and expressive language problems (Watkins et al., 2002a). Although rare, FOXP2 mutations have been found in a number of unrelated families and individuals with similar speech/language phenotypes (MacDermot et al., 2005; Feuk et al., 2006; Shriberg et al., 2006; Lennon et al., 2007; Palka et al., 2012; Rice et al., 2012; Zilina et al., 2012; for review, see Bacon and Rappold, 2012). In depth investigations of the KE family phenotype indicated a severe impairment in orofacial praxis tasks (Vargha-Khadem et al., 1995; Lai et al., 2001; Watkins 
et al., 2002a). In addition, impairments in language production tasks (e.g., phoneme addition, word repetition) were found between control and affected individuals (Vargha-Khadem et al., 1995). Different aspects of speech are thus impaired in KE family members (Watkins et al., 2002a). Orofacial praxis deficits underlie impaired lexicon building and subvocal (internal) speech representations which can affect irregular verb grammar (Doyon et al., 2003) and rule based grammar learning (Ullman, 2001). Thus, some of the language impairments in the $\mathrm{KE}$ family could be related to the core speech production deficits observed.

FOXP2, and its murine homolog Foxp2, are found across many regions of the developing and postnatal brain (FoxP2 will be used when referring to both species). Intriguing is the high expression of FoxP2 throughout the mouse and human cortico-striato-thalamic motor circuitry (Lai et al., 2003). During early development FoxP2 is broadly expressed in these regions, but in later developmental and postnatal stages expression becomes more restricted (Figure 1B depicts Foxp2 expression in the postnatal mouse brain). In adults, Foxp2 is limited to deep layer cortical neurons (layer 5 motor cortex and layer 6 throughout; Ferland et al., 2003; Morikawa et al., 2009; Hisaoka et al., 2010; Tomassy et al., 2010; Reimers-Kipping et al., 2011; Tsui et al., 2013). Within the striatum, Foxp2 is highly expressed in both types of MSN, though more commonly in D1R MSNs compared to D2R neurons (Vernes et al., 2011). Corresponding with its expression pattern, imaging studies have shown humans with FOXP2 mutations display structural and functional differences in motor areas. Affected members of the KE family showed structural gray matter volume differences in the motor cortex and striatum (Watkins et al., 2002b). Furthermore, functional imaging studies showed an underactivation of the striatum and altered cortical activation (including speech/motor areas such as the left anterior insular cortex) during word generation and word repetition tasks (Liegeois et al., 2003).

Converging evidence from FoxP2 expression pattern studies and phenotypic characterization of human mutations suggests that FOXP2 may play an important role in the development of the speech-motor pathway. The high expression of Foxp2 in a specific subset of neurons (D1R MSNs) in the striatum indicates a functional specificity related to motor tasks requiring the striatothalamic connections of the direct pathway. Malfunctions within this pathway could ultimately affect aspects of the motor circuitry related to fine motor control and contribute to the observed speech-motor deficit in humans.

\section{FOXP2 AS A MOLECULAR ENTRY POINT INTO SPEECH-MOTOR PATHWAYS}

FoxP2 is a transcription factor; its molecular function is to regulate the expression of other genes, switching them on or off in a temporally and spatially controlled manner. FoxP2 has been shown to regulate 100 s of different genes involved in processes crucial to brain development and function, ranging from neurogenesis and migration, to neurite outgrowth and synaptic activity (Spiteri et al., 2007; Vernes et al., 2007, 2011; Konopka et al., 2009; Devanna et al., 2014). Recently, evidence has suggested that FOXP2 regulates a number of genes involved in the retinoic acid (RA) signaling pathway (Devanna et al., 2014). RA is a vitamin-A derivative essential to mammalian development. Disruption of the RA signaling pathway (caused by genetic disruptions or dietary deficiencies) can have severe consequences during development and adulthood (Holson et al., 1997; Krezel et al., 1998)

Retinoic acid induces genetic and morphological changes in cells. When neuronal precursors (cells that generate neurons during development) differentiate into neurons they switch on genes normally found in mature neurons, stop dividing and grow long processes known as neurites (Siegenthaler et al., 2009; Korecka et al., 2013). We previously compared how neuronlike cells with or without FOXP2 responded to RA and found that cells showed stronger genetic and morphological changes in response to RA if FOXP2 was present (Devanna et al., 2014). In addition we discovered that FOXP2 changed the expression of RA receptors - proteins that directly control the cellular response to RA (Devanna et al., 2014). Of particular interest, FOXP2 upregulated retinoic acid receptor $\beta(\operatorname{RAR} \beta)$ and a number of other genes involved in transport or modification of RA were also transcriptionally regulated (e.g., ROR $\beta$, CRABPII, and ASCL1). These experiments suggest an intriguing link between FOXP2 and the RA pathway, in which FOXP2 seems to contribute to or modify the cellular response to RA.

Given the importance of the RA pathway for development, this raises new questions about how FOXP2 might mediate its effects on brain and neural circuit development. Could the relationship between FOXP2 and the RA pathway be relevant for (1) normal motor circuitry development and function, and/or (2) effects of FOXP2 dysfunction in patients? To address these questions, we need to understand how FoxP2 and the RA pathway might interact, and in what way FoxP2 mutations might affect the RA pathway on a cellular, functional and behavioral level.

\section{RA, FOXP2, AND MOTOR BEHAVIOR}

Retinoic acid is a key compound during embryogenesis, affecting a multitude of critical developmental pathways. Precise control of RA levels is essential for normal brain development as either an excess or a deficiency of RA results in widespread adverse effects on the brain.

Gestational treatment of rats with excess RA results in behavioral deficits in learning, memory and motor function (Holson et al., 1997). Rats treated with excess RA displayed poor generalized motor control including impairments in the 'righting reflex' (the ability to return to upright position), and the ability to sit only on the back paws. In addition, gestationally treated adult rats showed problems with learning and memory, such as decreased learning rates in a water filled T maze (Butcher et al., 1972; Holson et al., 1997). Rats lacking dietary vitamin A (of which RA is a metabolite) also perform poorly on motor learning 
and motor performance tasks (Carta et al., 2006). Furthermore, mice engineered to lack a key facilitator of RA signaling (RAR $\beta$ ) develop severe locomotion deficits and are highly impaired on motor learning tasks (Krezel et al., 1998).

The displayed motor deficits are similar to phenotypes observed in mouse models of Foxp2 dysfunction. Mouse models of two well characterized patient mutations of FOXP2 have been created that have comparable phenotypes. One mouse model reflects the $\mathrm{R} 553 \mathrm{H}$ missense mutation found in the KE family (Lai et al., 2001). The second mouse model mirrors an early stop codon in exon 7 introduced by a non-sense mutation that leads to a loss of FOXP2 protein in an independent family with speech/language disorder (MacDermot et al., 2005; Groszer et al., 2008). Mice that have a homozygous Foxp2 mutation show severe general motor impairments, reminiscent of animals treated with excess RA. However these Foxp2 homozygous mutants do not survive beyond 3-4 weeks after birth, possibly due to a requirement for Foxp2 in other organs such as the lungs or heart (Groszer et al., 2008). In mice where a single copy of Foxp2 is affected (as per the heterozygous state of the mutations observed in patients) general motor control is normal but motor learning is impaired (Groszer et al., 2008; French et al., 2012). This more subtle phenotype closely resembles the motor learning phenotype observed in RA deprived rats (Carta et al., 2006). For an overview of the different phenotypes exhibited by Foxp2 mutation, RAR mutation, and RA treatment, see Table 1.

\section{FOXP2 AND RA SIGNALING AFFECT NEURONAL FUNCTION}

In addition to the behavioral deficits, vitamin $\mathrm{A}$ deprivation/supplementation adversely affects striatal development and function. Cells in the developing lateral ganglionic eminence (the precursor region of the striatum) do not differentiate into the appropriate neuronal subtypes when RA signaling is blocked (Toresson et al., 1999; Chatzi et al., 2011). However restoring RA levels rescued this phenotype and resulted in normal differentiation into appropriate neuronal cell types (Chatzi et al., 2011). Separately, mice engineered to knockout the $R A R \beta$ gene display gross morphological striatal defects including impaired neurogenesis and deficits in acquiring proper neuronal identities (Liao et al., 2008). Lastly, chronic postnatal vitamin A supplementation has been linked to oxidative cell toxicity in the striatum (de Oliveira et al., 2007).

Foxp2 also contributes to striatal cell morphology and function. Foxp2 mutant neurons exhibit reduced neurite growth and branching in primary striatal cultures (Vernes et al., 2011) and the in vivo striatum displays aberrant neuronal activity. Mice with a heterozygous Foxp2 mutation showed unusually high activity in the dorsomedial striatum during active motor behavior (French et al., 2012). This suggests striatal cells can no longer properly modulate their activity following input from motor areas when lacking Foxp2. Moreover, the increased striatal activity normally seen when animals perform motor learning tasks was absent in mutant mice. Instead, a decrease in firing rate was seen, again suggesting aberrant modulation of responses to cortical and/or thalamic input (French et al., 2012). Additionally, extracellular measurements on striatal brain slices from heterozygous Foxp2 mutant animals show these cells fail to respond to induction of long term depression (LTD; Groszer et al., 2008). An inability to induce long term plasticity [either LTD or long term potentiation (LTP)] has debilitating consequences as scaled activity (plasticity) is necessary for circuits to properly regulate their input and output. Synaptic long term plasticity changes underlie information storage and are necessary for learning and memory (Novkovic et al., 2015; Zhu et al., 2015). Interestingly, in the striatum, synaptic plasticity has been strongly linked to motor learning (Dang et al., 2006; Kreitzer and Malenka, 2007). Defects specifically related to striatal LTD and LTP are known to affect procedural motor learning and the acquisition of new motor paradigms (Gubellini et al., 2004).

Aberrant induction of synaptic scaling has also been found in mice following acute RA depletion, which results in a complete lack of hippocampal LTP or LTD (Misner et al., 2001). This phenotype was specific to RA depletion and was reversible, as vitamin A supplementation rapidly restored normal synaptic plasticity (Misner et al., 2001). At a molecular level, RA signaling is mediated by the action of RA receptors (RARs; $\operatorname{RAR} \alpha, \operatorname{RAR} \beta$, and $\operatorname{RAR} \gamma$ ) and similar plasticity defects have been shown for mice lacking RAR $\alpha$ (Sarti et al., 2012) or RAR $\beta$ (Chiang et al., 1998). Hippocampal cells from these mice fail to establish LTD when subjected to low frequency stimulation - the paradigm necessary to induce LTD in the hippocampus. By contrast, excess RA induced the reverse effect in cultured hippocampal slices, where increased excitatory activity was observed (Aoto et al., 2008). It is not yet known if RA signaling affects synaptic plasticity in the striatum. However, the similarity in synaptic activity phenotypes between Foxp2-, RAR $\alpha$-, and RAR $\beta$-deficient animals (albeit focusing on different brain regions) does indicate these transcription factors may play a role in similar intracellular pathways regulating neuronal activity and synaptic plasticity.

The aforementioned plasticity (LTD and/or LTP) deficits in Foxp2, RAR $\alpha$, and RAR $\beta$ mutant animals suggests an improper reaction of neuronal circuits to changes in external input. Induction of LTD or LTP leads to a decrease or an increase, respectively, in the amount of glutamate receptors (of the AMPAreceptor class) at the synaptic membrane (Seidenman et al., 2003; Briand et al., 2014; for review, see Luscher and Huber, 2010). This change in AMPA receptor abundance modifies the response strength of a cell when it is excited. The change in stimulus-response strength is transient, and in time the normal AMPA receptor distribution will be restored, returning synaptic responses to normal levels. RA treatment of hippocampal cultures has shown an increase of AMPA receptors on the cell surface (Aoto et al., 2008), but no data on the striatum is currently present. The shared synaptic plasticity defect following disruption of RA signaling pathways or Foxp2 mutation does suggest that they both may influence receptor abundance or localization at the synapse in the striatum, an intriguing area for further study. 
TABLE 1 | Overview of phenotypes described in Foxp2 mutation, retinoic acid receptor (RAR) mutation and RA excess/depletion treatments.

\begin{tabular}{|c|c|c|c|c|c|}
\hline \multicolumn{2}{|r|}{ Deficit } & \multicolumn{2}{|c|}{ Foxp2 mutation } & \multirow{2}{*}{$\begin{array}{l}\text { RA receptor } \\
\text { mutation }\end{array}$} & \multirow{2}{*}{$\begin{array}{l}\text { RA excess/ } \\
\text { depletion }\end{array}$} \\
\hline & & Homozygous & Heterozygous & & \\
\hline \multirow{3}{*}{ 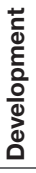 } & Embryogenesis defects & - & - & - & + \\
\hline & Lethality & ++ & - & + & ++ \\
\hline & $\begin{array}{l}\text { Aberrant basal ganglia } \\
\text { development }\end{array}$ & ++ & + & ++ & ++ \\
\hline \multirow{5}{*}{$\frac{\frac{\bar{\sigma}}{2}}{\frac{\bar{\sigma}}{0}}$} & Basal ganglia cell identity defects & NT & - & + & ++ \\
\hline & $\begin{array}{l}\text { Decreased neurite growth and } \\
\text { branching }\end{array}$ & ++ & NT & NT & NT \\
\hline & Aberrant neuronal activity in striatum & ++ & ++ & - & + \\
\hline & Unable to induce LTD & NT & ++ & ++ & NT \\
\hline & Unable to induce LTP & NT & NT & ++ & NT \\
\hline \multirow{3}{*}{ 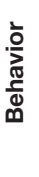 } & General motor control deficits & ++ & - & ++ & ++ \\
\hline & Motor learning deficits & $\begin{array}{c}\mathrm{N} / \mathrm{A} \\
\text { (postnatal lethality) }\end{array}$ & + & ++ & $\begin{array}{c}++ \\
\text { (postnatal treatment) }\end{array}$ \\
\hline & Spatial learning deficits & $\begin{array}{c}\mathrm{N} / \mathrm{A} \\
\text { (postnatal lethality) }\end{array}$ & NT & + & + \\
\hline
\end{tabular}

-, no effect; +, mild effect; ++, strong effect; N/A, not applicable; NT, not tested.

A thorough investigation of the mechanisms leading to LTD and LTP deficits resulting from RA/RAR and Foxp 2 malfunction will be necessary to understand if they function in the same pathways. Understanding the molecular mechanisms underlying striatal function, especially related to complex motor circuitry function, will lead to a better understanding of striatal speechmotor control.

\section{MOLECULAR LINKS BETWEEN RARS AND FOXP2}

Retinoic acid receptors canonically function as transcription factors, regulating genes responsible for directing normal embryogenesis and brain development. Interestingly, FoxP2 and RARs share some of the same target genes (Balmer and Blomhoff, 2002; Delacroix et al., 2010; Devanna et al., 2014). RARs are highly expressed in the brain (Krezel et al., 1999) and are present throughout embryonal development (Mollard et al., 2000), postnatal development (Wei et al., 2011), and in adults (Krezel et al., 1999; Zetterstrom et al., 1999). Notably high expression of RARs can be found throughout the motor circuitry, including cortical, striatal, and multiple thalamic regions (Krezel et al., 1999), (Figure 1B). We focus on two key receptors found in the motor circuitry: RAR $\alpha$ and RAR $\beta$. RAR $\alpha$ is found in layer 5 of the cortex and in the thalamus - both regions that overlap with murine Foxp2 expression (Krezel et al., 1999; Zetterstrom et al., 1999; Ferland et al., 2003; Lai et al., 2003; Hisaoka et al., 2010). Interestingly, Foxp 2 only overlaps with RAR $\alpha$ in the motor cortex layer 5, because Foxp2 expression is largely restricted to layer 6 of other mature cortical areas. RAR $\beta$ is strongly expressed only in the striatum, another site where Foxp2 expression is highest (Figure 1B). Notably, FOXP2 has been shown to directly drive RAR $\beta$ expression in human cells (Vernes et al., 2007; Devanna et al., 2014), although this is yet to be shown in the striatum. This high level of overlap, combined with shared target genes and molecular interactions, strongly supports interplay between FoxP2 and RARs in motor pathways.

\section{CONCLUDING REMARKS}

In addition to its canonical role during embryogenesis, studies described here suggest RA signaling plays a specific role in the development and function of striatal motor circuitry and may link to FoxP2 function. Disruption of the RA pathway results in strikingly similar phenotypes to FoxP2 mutation on multiple levels, which suggests a potential mechanistic interaction. FoxP2 and RARs can regulate some common target genes, affect similar cellular phenotypes and show highly overlapping expression patterns in the cortico-striato-thalamic motor circuitry. In the striatum, aberrant function of Foxp2 and RA signaling contributes to altered development and, in the case of mutations of mouse Foxp2, altered synaptic plasticity similar to that seen in the hippocampus of RAR $\alpha$ mutant animals. Given that RAR $\beta$ is predominantly expressed in the postnatal striatum, it seems likely that its disruption will also affect striatal plasticity, however, this is yet to be experimentally determined. Lastly, animals with mutated Foxp2 or RA signaling defects show comparable motor control/learning impairments. Thus at multiple levels (molecular, cellular, circuit, and behavioral) there is evidence that interplay between FoxP2 and RA signaling may facilitate proper development and function of motor circuitry. This evidence from mice is strengthened by findings in songbirds which show both FoxP2 and RA influence song learning by acting in circuits that have parallels with human vocal-motor pathways (Haesler et al., 2007; Wood et al., 2008). In the future it will be of great value to understand if these signaling cascades interact to influence neuronal mechanisms related to 
song learning or speech-motor control, and if RA signaling deficits are involved in aberrant speech-motor development in humans. The capacity for human speech and spoken language is dependent on multiple molecular and neural building blocks. With the link between FoxP2 and RA signaling, a new block has been suggested, giving us new opportunities to investigate the evolution and development of the (spoken) language ready brain.

\section{REFERENCES}

Albin, R. L., Young, A. B., and Penney, J. B. (1989). The functional-anatomy of basal ganglia disorders. Trends Neurosci. 12, 366-375. doi: 10.1016/01662236(89)90074-X

Aoto, J., Nam, C. I., Poon, M. M., Ting, P., and Chen, L. (2008). Synaptic signaling by all-trans retinoic acid in homeostatic synaptic plasticity. Neuron 60, 308-320. doi: 10.1016/j.neuron.2008.08.012

Bacon, C., and Rappold, G. A. (2012). The distinct and overlapping phenotypic spectra of FOXP1 and FOXP2 in cognitive disorders. Hum. Genet. 131, $1687-$ 1698. doi: 10.1007/s00439-012-1193-z

Balmer, J. E., and Blomhoff, R. (2002). Gene expression regulation by retinoic acid. J. Lipid Res. 43, 1773-1808. doi: 10.1194/jlr.R100015-JLR200

Booth, J. R., Wood, L., Lu, D., Houk, J. C., and Bitan, T. (2007). The role of the basal ganglia and cerebellum in language processing. Brain Res. 1133, 136-144. doi: 10.1016/j.brainres.2006.11.074

Briand, L. A., Kimmey, B. A., Ortinski, P. I., Huganir, R. L., and Pierce, R. C. (2014). Disruption of glutamate receptor-interacting protein in nucleus accumbens enhances vulnerability to cocaine relapse. Neuropsychopharmacology 39, 759769. doi: $10.1038 /$ npp. 2013.265

Butcher, R. E., Brunner, R. L., Roth, T., and Kimmel, C. A. (1972). Learning impairment associated with maternal hypervitaminosis-a in rats. Life Sci. 11, 141-145. doi: 10.1016/0024-3205(72)90227-5

Calabresi, P., Picconi, B., Tozzi, A., Ghiglieri, V., and Di Filippo, M. (2014). Direct and indirect pathways of basal ganglia: a critical reappraisal. Nat. Neurosci. 17, 1022-1030. doi: 10.1038/nn.3743

Carta, M., Stancampiano, R., Tronci, E., Collu, M., Usiello, A., Morelli, M., et al. (2006). Vitamin A deficiency induces motor impairments and striatal cholinergic dysfunction in rats. Neuroscience 139, 1163-1172. doi: 10.1016/j.neuroscience.2006.01.027

Chatzi, C., Brade, T., and Duester, G. (2011). Retinoic acid functions as a key GABAergic differentiation signal in the basal ganglia. PLoS Biol. 9:e1000609. doi: 10.1371/journal.pbio.1000609

Chiang, M. Y., Misner, D., Kempermann, G., Schikorski, T., Giguere, V., Sucov, H. M., et al. (1998). An essential role for retinoid receptors RAR beta and RXR gamma in long-term potentiation and depression. Neuron 21, 1353-1361. doi: 10.1016/S0896-6273(00)80654-6

Craig-McQuaide, A., Akram, H., Zrinzo, L., and Tripoliti, E. (2014). A review of brain circuitries involved in stuttering. Front. Hum. Neurosci. 8:884. doi: 10.3389/fnhum.2014.00884

Dang, M. T., Yokoi, F., Yin, H. H., Lovinger, D. M., Wang, Y. Y., and Li, Y. Q. (2006). Disrupted motor learning and long-term synaptic plasticity in mice lacking NMDAR1 in the striatum. Proc. Natl. Acad. Sci. U.S.A. 103, 15254-15259. doi: 10.1073/pnas.06017 58103

Delacroix, L., Moutier, E., Altobelli, G., Legras, S., Poch, O., Choukrallah, M. A., et al. (2010). Cell-specific interaction of retinoic acid receptors with target genes in mouse embryonic fibroblasts and embryonic stem cells. Mol. Cell. Biol. 30, 231-244. doi: 10.1128/MCB.00756-09

de Oliveira, M. R., De Bittencourt Pasquali, M. A., Silvestrin, R. B., Mello E Souza, T., and Moreira, J. C. (2007). Vitamin A supplementation induces a prooxidative state in the striatum and impairs locomotory and exploratory activity of adult rats. Brain Res. 1169, 112-119. doi: 10.1016/j.brainres.2007.07.008

Devanna, P., Middelbeek, J., and Vernes, S. C. (2014). FOXP2 drives neuronal differentiation by interacting with retinoic acid signaling pathways. Front. Cell. Neurosci. 8:305. doi: 10.3389/fncel.2014.00305

\section{ACKNOWLEDGMENTS}

This work was supported by a grant from the Donders Institute, Radboud University Nijmegen, a Marie Curie career development grant awarded to SCV and by the Max Planck Society. We would like to thank Moritz Negwer for valuable comments on the manuscript.

Doyon, J., Penhune, V., and Ungerleider, L. G. (2003). Distinct contribution of the cortico-striatal and cortico-cerebellar systems to motor skill learning. Neuropsychologia 41, 252-262. doi: 10.1016/S0028-3932(02)0 0158-6

Ferland, R. J., Cherry, T. J., Preware, P. O., Morrisey, E. E., and Walsh, C. A. (2003). Characterization of Foxp2 and Foxp1 mRNA and protein in the developing and mature brain. J. Compar. Neurol. 460, 266-279. doi: 10.1002/cne.10654

Feuk, L., Kalervo, A., Lipsanen-Nyman, M., Skaug, J., Nakabayashi, K., Finucane, B., et al. (2006). Absence of a paternally inherited FOXP2 gene in developmental verbal dyspraxia. Am. J. Hum. Genet. 79, 965-972. doi: $10.1086 / 508902$

Fisher, S. E., Vargha-Khadem, F., Watkins, K. E., Monaco, A. P., and Pembrey, M. E. (1998). Localisation of a gene implicated in a severe speech and language disorder. Nat. Genet. 18, 168-170. doi: 10.1038/ng0298-168

French, C. A., Jin, X., Campbell, T. G., Gerfen, E., Groszer, M., Fisher, S. E., et al. (2012). An aetiological Foxp2 mutation causes aberrant striatal activity and alters plasticity during skill learning. Mol. Psychiatry 17, 1077-1085. doi: 10.1038/mp.2011.105

Groszer, M., Keays, D. A., Deacon, R. M. J., De Bono, J. P., Prasad-Mulcare, S., Gaub, S., et al. (2008). Impaired synaptic plasticity and motor learning in mice with a point mutation implicated in human speech deficits. Curr. Biol. 18, 354-362. doi: 10.1016/j.cub.2008.01.060

Gubellini, P., Pisani, A., Centonze, D., Bernardi, G., and Calabresi, P. (2004). Metabotropic glutamate receptors and striatal synaptic plasticity: implications for neurological diseases. Prog. Neurobiol. 74, 271-300. doi: 10.1016/j.pneurobio.2004.09.005

Haesler, S., Rochefort, C., Georgi, B., Licznerski, P., Osten, P., and Scharff, C. (2007). Incomplete and inaccurate vocal imitation after knockdown of FoxP2 in songbird basal ganglia nucleus Area X. PLoS Biol. 5:e321. doi: 10.1371/journal.pbio.0050321

Hisaoka, T., Nakamura, Y., Senba, E., and Morikawa, Y. (2010). The forkhead transcription factors, Foxp1 and Foxp2, identify different subpopulations of projection neurons in the mouse cerebral cortex. Neuroscience 166, 551-563. doi: 10.1016/j.neuroscience.2009.12.055

Holson, R. R., Gazzara, R. A., Ferguson, S. A., and Adams, J. (1997). Behavioral effects of low-dose gestational day 11-13 retinoic acid exposure. Neurotoxicol. Teratol. 19, 355-362. doi: 10.1016/S0892-0362(97)00041-X

Huang, Q., Zhou, D., Chase, K., Gusella, J. F., Aronin, N., and Difiglia, M. (1992). Immunohistochemical localization of the D1 dopamine receptor in rat-brain reveals its axonal-transport, presynaptic and postsynaptic localization, and prevalence in the basal ganglia, limbic system, and thalamic reticular nucleus. Proc. Natl. Acad. Sci. U.S.A. 89, 11988-11992. doi: 10.1073/pnas.89.24.1 1988

Hurst, J. A., Baraitser, M., Auger, E., Graham, F., and Norell, S. (1990). An extended family with a dominantly inherited speech disorder. Dev. Med. Child Neurol. 32, 352-355. doi: 10.1111/j.1469-8749.1990.tb16948.x

Kemp, J. M., and Powell, T. P. S. (1971). Termination of fibres from cerebral cortex and thalamus upon dendritic spines in caudate nucleus - study with golgi method. Philos. Trans. R. Soc. Lond. B Biol. Sci. 262, 429-439. doi: 10.1098/rstb.1971.0105

Konopka, G., Bomar, J. M., Winden, K., Coppola, G., Jonsson, Z. O., Gao, F. Y., et al. (2009). Human-specific transcriptional regulation of CNS development genes by FOXP2. Nature 462, U213-U289. doi: 10.1038/nature08549

Korecka, J. A., Van Kesteren, R. E., Blaas, E., Spitzer, S. O., Kamstra, J. H., Smit, A. B., et al. (2013). Phenotypic characterization of retinoic acid differentiated sh-sy5y cells by transcriptional profiling. PLoS ONE 8:e63862. doi: 10.1371/journal.pone.0063862 
Kravitz, A. V., and Kreitzer, A. C. (2012). Striatal mechanisms underlying movement, reinforcement, and punishment. Physiology 27, 167-177. doi: 10.1152/physiol.00004.2012

Kreitzer, A. C., and Malenka, R. C. (2007). Endocannabinoid-mediated rescue of striatal LTD and motor deficits in Parkinson's disease models. Nature 445, 643-647. doi: 10.1038/nature05506

Kreitzer, A. C., and Malenka, R. C. (2008). Striatal plasticity and basal ganglia circuit function. Neuron 60, 543-554. doi: 10.1016/j.neuron.2008.1 1.005

Krezel, W., Ghyselinck, N., Samad, T. A., Dupe, V., Kastner, P., Borrelli, E., et al. (1998). Impaired locomotion and dopamine signaling in retinoid receptor mutant mice. Science 279, 863-867. doi: 10.1126/science.279.5 352.863

Krezel, W., Kastner, P., and Chambon, P. (1999). Differential expression of retinoid receptors in the adult mouse central nervous system. Neuroscience 89, 1291 1300. doi: 10.1016/S0306-4522(98)00342-X

Lai, C. S. L., Fisher, S. E., Hurst, J. A., Vargha-Khadem, F., and Monaco, A. P. (2001). A forkhead-domain gene is mutated in a severe speech and language disorder. Nature 413, 519-523. doi: 10.1038/35097076

Lai, C. S., Gerrelli, D., Monaco, A. P., Fisher, S. E., and Copp, A. J. (2003). FOXP2 expression during brain development coincides with adult sites of pathology in a severe speech and language disorder. Brain 126, 2455-2462. doi: 10.1093/brain/awg247

Lennon, P. A., Cooper, M. L., Peiffer, D. A., Gunderson, K. L., Patel, A., Peters, S., et al. (2007). Deletion of 7q31-1 supports involvement of FOXP2 in language impairment: clinical report and review. Am. J. Med. Genet. Part A 143a, 791-798. doi: 10.1002/ajmg.a.31632

Liao, W. L., Tsai, H. C., Wang, H. F., Chang, J., Lu, K. M., Wu, H. L., et al. (2008). Modular patterning of structure and function of the striatum by retinoid receptor signaling. Proc. Natl. Acad. Sci. U.S.A. 105, 6765-6770. doi: 10.1073/pnas.0802109105

Lieberman, P. (2002). On the nature and evolution of the neural bases of human language. Am. J. Phys. Anthropol. 45, 36-62. doi: 10.1002/ajpa.10171

Lieberman, P. (2007). The evolution of human speech - Its anatomical and neural bases. Curr. Anthropol. 48, 39-66. doi: 10.1098/rstb.201 1.0099

Liegeois, F., Baldeweg, T., Connelly, A., Gadian, D. G., Mishkin, M., and VarghaKhadem, F. (2003). Language fMRI abnormalities associated with FOXP2 gene mutation. Nat. Neurosci. 6, 1230-1237. doi: 10.1038/nn1138

Luscher, C., and Huber, K. M. (2010). Group 1 mGIuR-dependent synaptic long-term depression: mechanisms and implications for circuitry and disease. Neuron 65, 445-459. doi: 10.1016/j.neuron.2010.01.016

MacDermot, K. D., Bonora, E., Sykes, N., Coupe, A. M., Lai, C. S. L., Vernes, S. C., et al. (2005). Identification of FOXP2 truncation as a novel cause of developmental speech and language deficits. Am. J. Hum. Genet. 76, 1074-1080. doi: $10.1086 / 430841$

Misner, D. L., Jacobs, S., Shimizu, Y., De Urquiza, A. M., Solomin, L., Perlmann, T., et al. (2001). Vitamin A deprivation results in reversible loss of hippocampal long-term synaptic plasticity. Proc. Natl. Acad. Sci. U.S.A. 98, 11714-11719. doi: 10.1073/pnas.191369798

Mollard, R., Viville, S., Ward, S. J., Decimo, D., Chambon, P., and Dolle, P. (2000). Tissue-specific expression of retinoic acid receptor isoform transcripts in the mouse embryo. Mech. Dev. 94, 223-232. doi: 10.1016/S0925-4773(00)0 0303-8

Morikawa, Y., Hisaoka, T., and Senba, E. (2009). Characterization of Foxp2expressing cells in the developing spinal cord. Neuroscience 162, 1150-1162. doi: 10.1016/j.neuroscience.2009.05.022

Novkovic, T., Shchyglo, O., Gold, R., and Manahan-Vaughan, D. (2015). Hippocampal function is compromised in an animal model of multiple sclerosis. Neuroscience 309, 100-112. doi: 10.1016/j.neuroscience.2015. 03.008

Ogar, J. M., Dronkers, N. F., Brambati, S. M., Miller, B. L., and GornoTempini, M. L. (2007). Progressive nonfluent aphasia and its characteristic motor speech deficits. Alzheimer Dis. Assoc. Disord. 21, S23-S30. doi: 10.1097/WAD.0b013e31815d19fe

Palka, C., Alfonsi, M., Mohn, A., Cerbo, R., Franchi, P. G., Fantasia, D., et al. (2012). Mosaic 7q31 deletion involving FOXP2 gene associated with language impairment. Pediatrics 129, E183-E188. doi: 10.1542/peds.2010-2094
Reimers-Kipping, S., Hevers, W., Paabo, S., and Enard, W. (2011). Humanized Foxp2 specifically affects cortico-basal ganglia circuits. Neuroscience 175, 75-84. doi: 10.1016/j.neuroscience.2010.11.042

Rice, G. M., Raca, G., Jakielski, K. J., Laffin, J. J., Iyama-Kurtycz, C. M., Hartley, S. L., et al. (2012). Phenotype of FOXP2 haploinsufficiency in a mother and Son. Am. J. Med. Genet. Part A 158a, 174-181. doi: 10.1002/ajmg.a.34354

Sarti, F., Schroeder, J., Aoto, J., and Chen, L. (2012). Conditional RAR alpha knockout mice reveal acute requirement for retinoic acid and RAR alpha in homeostatic plasticity. Front. Mol. Neurosci. 5:16. doi: $10.3389 /$ fnmol.2012.00016

Seidenman, K. J., Steinberg, J. P., Huganir, R., and Malinow, R. (2003). Glutamate receptor subunit 2 serine 880 phosphorylation modulates synaptic transmission and mediates plasticity in CA1 pyramidal cells. J. Neurosci. 23, 9220-9228.

Shriberg, L. D., Ballard, K. J., Tomblin, J. B., Duffy, J. R., Odell, K. H., and Williams, C. A. (2006). Speech, prosody, and voice characteristics of a mother and daughter with a 7;13 translocation affecting FOXP2. J. Speech Lang. Hear. Res. 49, 500-525. doi: 10.1044/1092-4388(2006/038)

Siegenthaler, J. A., Ashique, A. M., Zarbalis, K., Patterson, K. P., Hecht, J. H., Kane, M. A., et al. (2009). Retinoic acid from the meninges regulates cortical neuron generation. Cell 139, 597-609. doi: 10.1016/j.cell.2009.10.004

Spiteri, E., Konopka, G., Coppola, G., Bomar, J., Oldham, M., Ou, J., et al. (2007). Identification of the transcriptional targets of FOXP2, a gene linked to speech and language, in developing human brain. Am. J. Hum. Genet. 81, 1144-1157. doi: 10.1086/522237

Tomassy, G. S., De Leonibusa, E., Jabaudon, D., Lodato, S., Alfano, C., Mele, A., et al. (2010). Area-specific temporal control of corticospinal motor neuron differentiation by COUP-TFI. Proc. Natl. Acad. Sci. U.S.A. 107, 3576-3581. doi: 10.1073/pnas.0911792107

Toresson, H., Mata De Urquiza, A., Fagerstrom, C., Perlmann, T., and Campbell, K. (1999). Retinoids are produced by glia in the lateral ganglionic eminence and regulate striatal neuron differentiation. Development 126, 1317-1326.

Tsui, D., Vessey, J. P., Tomita, H., Kaplan, D. R., and Miller, F. D. (2013). FoxP2 Regulates Neurogenesis during Embryonic Cortical Development. J. Neurosci. 33, 244-258. doi: 10.1523/JNEUROSCI.1665-12.2013

Ullman, M. T. (2001). The declarative/procedural model of lexicon and grammar. J. Psycholinguist. Res. 30, 37-69. doi: 10.1023/A:1005204207369

Vargha-Khadem, F., Watkins, K., Alcock, K., Fletcher, P., and Passingham, R. (1995). Praxic and nonverbal cognitive deficits in a large family with a genetically transmitted speech and language disorder. Proc. Natl. Acad. Sci. U.S.A. 92, 930-933. doi: 10.1073/pnas.92.3.930

Vernes, S. C., Oliver, P. L., Spiteri, E., Lockstone, H. E., Puliyadi, R., Taylor, J. M., et al. (2011). Foxp2 regulates gene networks implicated in neurite outgrowth in the developing brain. PLos Genet. 7:e1002145. doi: 10.1371/journal.pgen.1002145

Vernes, S. C., Spiteri, E., Nicod, J., Groszer, M., Taylor, J. M., Davies, K. E., et al. (2007). High-throughput analysis of promoter occupancy reveals direct neural targets of FOXP2, a gene mutated in speech and language disorders. Am. J. Hum. Genet. 81, 1232-1250. doi: 10.1086/522238

Watkins, K. E., Dronkers, N. F., and Vargha-Khadem, F. (2002a). Behavioural analysis of an inherited speech and language disorder: comparison with acquired aphasia. Brain 125(pt 3), 452-464. doi: 10.1093/brain/awf058

Watkins, K. E., Vargha-Khadem, F., Ashburner, J., Passingham, R. E., Connelly, A., Friston, K. J., et al. (2002b). MRI analysis of an inherited speech and language disorder: structural brain abnormalities. Brain 125(pt 3), 465-478. doi: 10.1093/brain/awf057

Wei, J. A., Yi, W. E., Min, G., Yuan, S., Li, C., Yang, B., et al. (2011). The pattern of retinoic acid receptor expression and subcellular, anatomic and functional area translocation during the postnatal development of the rat cerebral cortex and white matter. Brain Res. 1382, 77-87. doi: 10.1007/s00221-011-2873-y

Wildgruber, D., Ackermann, H., and Grodd, W. (2001). Differential contributions of motor cortex, basal ganglia, and cerebellum to speech motor control: effects of syllable repetition rate evaluated by fMRI. Neuroimage 13, 101-109. doi: 10.1006/nimg.2000.0672

Wood, W. E., Olson, C. R., Lovell, P. V., and Mello, C. V. (2008). Dietary retinoic acid affects song maturation and gene expression in the song system of the zebra finch. Dev. Neurobiol. 68, 1213-1224. doi: 10.1002/dneu.20642

Zetterstrom, R. H., Lindqvist, E., De Urquiza, A. M., Tomac, A., Eriksson, U., Perlmann, T., et al. (1999). Role of retinoids in the CNS: differential expression 
of retinoid binding proteins and receptors and evidence for presence of retinoic acid. Euro. J. Neurosci. 11, 407-416. doi: 10.1046/j.1460-9568.1999.00 444.x

Zhu, D., Li, C. C., Swanson, A. M., Villalba, R. M., Guo, J. D., Zhang, Z. B., et al. (2015). BAI1 regulates spatial learning and synaptic plasticity in the hippocampus. J. Clin. Investig. 125, 1497-1508. doi: 10.1172/JCI74603

Zilina, O., Reimand, T., Zjablovskaja, P., Mannik, K., Mannamaa, M., Traat, A., et al. (2012). Maternally and paternally inherited deletion of 7q31 involving the FOXP2 gene in two families. Am. J. Med. Genet. Part A 158a, 254-256. doi: 10.1002/ajmg.a.34378
Conflict of Interest Statement: The authors declare that the research was conducted in the absence of any commercial or financial relationships that could be construed as a potential conflict of interest.

Copyright $\odot 2015$ van Rhijn and Vernes. This is an open-access article distributed under the terms of the Creative Commons Attribution License (CC BY). The use, distribution or reproduction in other forums is permitted, provided the original author(s) or licensor are credited and that the original publication in this journal is cited, in accordance with accepted academic practice. No use, distribution or reproduction is permitted which does not comply with these terms. 